\title{
Are we entering a golden age for changing lives in sports and exercise medicine?
}

\author{
Steve Aspinall
}

\section{ARE WE ENTERING A GOLDEN AGE FOR CHANGING LIVES IN SPORTS AND EXERCISE MEDICINE?}

It is an exciting time to be working in healthcare and medicine! Despite the myriad of challenges, the opportunities we have to genuinely and lastingly change people's lives for the better are legion. How many professions have the opportunity to change a person's current health, future health, sports and work performance alongside having a positive impact on social and family life? To enable us to do this we need not only the right knowledge and skill set, but we also need to be able to apply it to our patients in the real world, without becoming bogged down in seeing patients only as a specific pathology or an injury to treat. They are so much more than that and so are we. This issue of the British Journal of Sports Medicine (BJSM) offers real world application of knowledge that can change many areas of our practice with lots of clear take home messages. If you are new to this, check out the BJSM social media including Facebook, Twitter, podcasts, blog and YouTube (hence the front cover feature, figure 1).

Supporting the BJSM community is a shift in culture. Regardless of the driver, health is evermore in the public eye and doctors like Sarah Hallberg (featured in this issue), Aseem Malhotra and Michael Mosley are popular figures in the media. Other fantastic examples of change include the well deserved - stratospheric growth from the grass roots level of The Daily Mile. In a short time it has now been taken up by more than 3200 schools across the UK and Europe. This is a really valuable vehicle for change starting with our children (https:// thedailymile.co.uk). Professionally, the excellent Movement4Movement educational resources and community of practice approach are giving medical and healthcare professionals the tools they need to improve the health of society. More information can be found in the 2017 BJSM podcast (https://soundcloud.com/bmjpodcasts/ physical-activity-in-the-curriculum-impactin-schools-of-medicine-and-new-healthcare-professionals).

Correspondence to Steve Aspinall, School of Health Sciences, University of Salford, Manchester M6 6PU, UK; S.J.Aspinall@salford.ac.uk

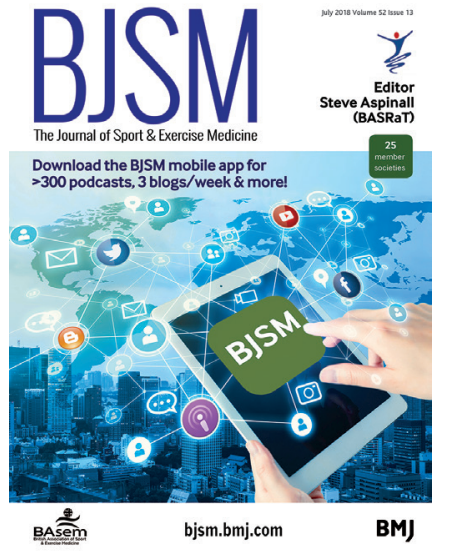

Figure 1 Facebook, Twitter, podcasts, blog and YouTube are essential elements of BJSM's mission to improve prevention, practice and perceptions in the sports medicine community.

\section{WHAT'S NEW IN THIS BASRAT GUIDED ISSUE?}

Sarah Hallberg's education review based on her phenomenally successful TED talk examines the controversy that surrounds nutritional guidelines and discusses how low carbohydrate diets can treat and in many cases reverse type two diabetes along with improving cardiovascular health (see page 869).

The other cornerstone of good health is physical activity and exercise, although the dose-response relationship has remained somewhat elusive. We know it has a significant positive effect on cardiovascular disease risk factors, but how much exactly is needed to achieve these benefits? I highlight the systematic review and meta-regression by Finnish professor, Pekka Oja, and colleagues who examined walking interventions in last month's special BJSM/ISPAH (International Society for Physical Activity and Health) issue on walking. A large range of met-minutes can benefit cardiovascular disease risk factors (bjsports-2017-098558). Those of us in the UK can attend their 2018 conference in London (@ISPAH and www.ispah.org).

In addition to understanding the dose response relationship of exercise, it is crucial that we, as sports and exercise medicine professionals, recognise and understand the dimensions of physical activity. In their editorial, Perth's Professor Leon Straker and colleagues discuss this in detail and guide us through the 'Goldilocks Principal', a practical way to design physical activity at work to be 'just right' for improving health; this has lots of transferable messages too (see page 818).

Back in 2015, England Athletics estimated that there were 2.5 million people taking part in athletics each week, a number that has likely increased over the last couple of years. As we encourage more people to exercise it is inevitable that in activities like running there is the potential for a significantly increased incidence of running related injuries. In a pragmatic randomised controlled trial, Luiz Hespanhol and colleagues from the Amsterdam Collaboration on Health and Safety in Sports, determined the effectiveness of adding online tailored advice to general advice in Dutch trail runners on running related injuries (see page 851). Highlighting the importance of expert advice in this population, they found that runners in the intervention group sustained 13\% fewer running injuries than the control group. Canada's Jean-Francois Esculier and colleagues follow this up with an excellent related infographic (see page 824).

Other highlights in this issue include an editorial on holistic hamstring health by Aiden Oakley and colleagues (see page 816), an education review by Mark Sinque and colleagues on meniscal root tears (see page 872) and a systematic review and meta-analysis by Neil Smart and colleagues (see page 834) looking at exercise training and liver function, the results of which highlight the response of the dose-response relationship for a variety of different health parameters.

\section{ABOUT BASRAT}

BASRaT is the UK regulator for sport and exercise rehabilitators and an advocate of the multidisciplinary healthcare team, guiding sport rehabilitators on all aspects of their role and responsibilities, ensuring public protection, professional competency and continued professional development. You can follow us on Twitter@BASRaTorg

The BASRaT register has been approved as an accredited register by the Professional Standards Authority for Health and Social Care (www.basrat.org).

Competing interests None declared.

Patient consent Not required.

Provenance and peer review Commissioned; internally peer reviewed.

(c) Article author(s) (or their employer(s) unless otherwise stated in the text of the article) 2018. All rights reserved. No commercial use is permitted unless otherwise expressly granted.

$$
\text { D Check for updates }
$$

To cite Aspinall S. Br J Sports Med 2018;52:815

Br J Sports Med 2018;52:815

doi:10.1136/bjsports-2018-099576 